園学雑. (J. Japan. Soc. Hort. Sci.) 62(3) : 595-600. 1993.

\title{
ファレノプシスの花成誘導前の光強度が花成誘導時の 温度感応性におよぼす影響
}

\author{
窪田＼cjkstart聡・米田和夫
}

日本大学農獣医学部 252 藤沢市亀井野 1866

Effect of Light Intensity Preceding Day/Night Temperatures on the Sensitivity of Phalaenopsis to Flower

Satoshi Kubota and Kazuo Yoneda

College of Agriculture and Veterinary Medicine, Nihon University, Fujisawa, Kanagawa 252

\section{Sammary}

The effects of high, moderate, and low light intensities on floral induction and nitrogen nutrition in Phalaenopsis grown at $23 \% 18{ }^{\circ} \mathrm{C}, 28 \% / 23^{\circ} \mathrm{C}$, and $33 \% / 28{ }^{\circ} \mathrm{C}$ (day/night) were ascertained.

1. High light intensity substantially increased total dry matter, sugar content, and ni. trogen absorbed. The differential in $C$ assimilation and $N$ uptake resulted in larger plants having lower $\mathrm{N}$ content under high light intensity.

2. The number of expanded leaves, the growth of roots, and the amount of dry matter produced per plant increased under proportionately higher light intensities.

3. High light intensity preceding $23 \% / 18^{\circ} \mathrm{C}$ treatment increased the number of inflorescence, but the $28^{\circ} / 23^{\circ} \mathrm{C}$ treatment advanced their time of emergence to plant ex. posed to lower light intensities. The temperature sensitivity for floral induction increased in those plants which produced relatively more dry matter per unit $N$ absorbed (larger $\mathrm{C} / \mathrm{N}$ balance).

To increase the sensitivity of Phalaenopsis plants to floral induction, they should be grown under high light intensity; because these conditions lead to high sugar content. which in turn, seemingly expedite rapid metabolism of nitrogen.

\section{緒言}

ファレノプシスの花成誘導の主要因は, $20^{\circ} \mathrm{C}$ 前後 の温度であることが明かとなり（石田・坂西 1974; Sakanishi ら，1980)，この特性を利用した温度処理に よる開花調節技術の実用化により（樋口・酒井, 1978; 米田，1985)，ほぼ周年にわたる出荷が可能にな った。しかし，促成栽培では花成誘導をより安定的に もたらすために，夏期に冷房設備による処理温度を $20^{\circ} \mathrm{C}$ 以下に設定する場合が多く，この時強遮光によ り施設内の光強度が不十分になるなどの問題がある。

1992 年 11 月 2 日 受理.

本報告の概要は, 1992 年の園芸学会春季大会において 口頭発表した。

フォレノプシスの生育・開花に関する植物栄羙生理学的 研究 第 3 報
光強度と花成誘導の関係についての研究は少なく (井上, 1988)，末だ十分な栽培指針となる知見は得ら れていないのが現状である。

そこで，本実験は花成誘導前の生育期間中の光強度 が, 花成誘導の温度感応性におよぼす影響について植 物栄養生理学的な側面加検討し, 花成誘導をより効 率的にするための光条件を知ることを目的として行っ たものである.

\section{材料および方法}

材料は桃色系 Phalaenopsis (Malibu victory $\times$ Arai) $\times$ Phal. (Joseph Hampton 'Diane' $\times$ Naughty Pink 'Extra') の自殖実生株と, 白色系 Phal. Miki Saito 03 年生実生未開花株で，夏期は 75\%，冬期は 50\%の遮 光条件下の本学実験温室内で栽培管理されていたもの である。これらの株は，1991 年 3 月下旬に 3.5 号の 
素焼鉢にミズゴケ単用植えにした。この時全供試株の 新鮮重を測定すると同時に，分析のためにこの中から 両交配種を 3 株ずつ採取した，供試株数は，光処理区 当たり生育調查株として両交配種合わせて 36 株，分 析用株は両交配種合わせて 6 株用いた。

試験区は，遮光率 $50 \%$ の黑寒冷紗 1 枚で遮光した 日本大学農獣医学部（神奈川県藤沢市）のガラス温室 内を強光区とし，同寒冷秒 2 枚で遮光した中光区，同 寒冷紗 3 枚で遮光した弱光区の 3 区を設けた，光処理 は，1991年 5 月 3 日から 8 月 11 日まで行った。

各光処理区の光強度は, 光処理期間中にほぼ 4 日ご とに正午に照度計（東京光学機械: 光電池照度計 SPI-71) で測定し，この測定値に係数を掛けて光量子 束密度に換算（稲田，1984）して示した。

花成誘導のための温度処理は，昼温／夜温を $8 / 16$ 時間の変温管理とし, $23 \% 18{ }^{\circ} \mathrm{C}, 28 \% / 23^{\circ} \mathrm{C}, 33 \% / 28$ ${ }^{\circ} \mathrm{C}$ の 3 段階に設定したファイトトロン (小系工業製, コイトトロン $3 \mathrm{~S}-313 \mathrm{~A}$ 特殊型）を 3 室使用した。温 度処理は，同年 8 月 12 日に各光処理区から 12 株ずつ ファイトトロンへ移入して開始し，10月 2 日までの 51 日間行った. 温度処理中および処理後の光管理は, 各区とも同寒冷紗 2 枚被覆に統一した。

培盖液は同年 5 月 7 日，6月 1 日，7月 6 日に，園 試標準培盖液（山崎，1982）を $150 \mathrm{ml}$ 施用した。 か ん水用水は水道水を使用し, 培地の水分張力が約 $\mathrm{pF}$ 2.4 になった時点で 1 鉢当たり $200 \mathrm{ml}$ かん水した。

生育調査は，実験開始後 1 か月ごとに葉長，葉幅， 葉枚数を測定した。あらかじめ各交配種ごとに求めた 葉長と葉幅の積と葉面積との間に極めて高い相関関係 (桃色系: $r=0.965^{* *}$, 白花系: $r=0.991^{* *}$ ) 加認女 られたので，実験期間中の菜面積は得られた一次回帰 式（桃色系: $y=0.751 \times$ 葉長 $\times$ 葉幅, 白花系: $y=$ $0.739 \times$ 葉長 $\times$ 葉幅）に当てはめ算出した。なお，生
育調查の結果は, 実験開始から8月 3 日までの 3 か月 間の增加量として示した.

株の栄養状態と光強度の関係を明らかにするために, 温度処理直前の 8 月 12 日に各光処理区につき両交配 種を 3 株ずつ採取した，採取した株は葉，茎，根の各 部位に分割し, $70^{\circ} \mathrm{C}$ で通風乾燥後粉砕し, 乾燥粉研 試料とした。

還元糖は，乾燥粉砕試料を $80 \%$ 熱エ夕ノール抽出 後, ソモギーネルソン法（福井，1990）によって定量 し，全糖は抽出液を $4 \%$ 硫酸で加水分解後（吉野， 1975），4\%水酸化ナトリウムで中和し同法により定量 した．全窒素は，乾燥粉砕試料をサリチル硫酸一過酸 化水素分解法（松永・塩崎，1989）により分解し，イ ンドフェノール青法（大山，1990）により定量した. 不溶性窒素は, 糖抽出残さを上記の方法により分解し て定单し, 可溶性窒素は全絰素から不溶性窒素を差し 引いて求めた。

実験開始時の全供試株の乾物重は，各株の新鮮重に 実験開始直前に採取した株の乾物率を乗じて推定した (第 1 表)，乾物生産量は，8月に採取した株の乾物重 から実験開始時の推定乾物重（第 1 表）を差し引いて 求めた，窒素吸収量は 8 月に採取した株の全窒素含有 量から，実験開始時の推定乾物重 $\times$ 実験開始時の全等 素含有率として算出した実験前の推定塋素含有量を差 し引いて求めた.

な扔，生育，花成誘導ならびに栄養状態について統 計処理をした結果, 品種間差はほとんど認められなか ったので，これらの結果は両品種をまとめて表記した。

\section{結果および考察}

\section{1. 実験期間中の光強度と温室内気温}

強光区の光強度は, $5 \sim 6$ 月に最大 $300 \mu \mathrm{mol} \cdot \mathrm{m}^{-2}$ $\cdot \mathrm{sec}^{-1}, 7$ 月下旬には最大 $400 \mu \mathrm{mol} \cdot \mathrm{m}^{-2} \cdot \mathrm{sec}^{-1}$ 以上となった（第1図）．処理間の差は晴天時には大

Table 1. Average fresh weight, estimated dry weight, number of leaves and leaf area of the plants used as materials before the light intensity treatments.

\begin{tabular}{|c|c|c|c|c|}
\hline $\begin{array}{l}\text { Light } \\
\text { intensity }^{z}\end{array}$ & $\begin{array}{l}\text { Average } \\
\text { fresh weight } \\
(\mathrm{g} / \text { plant }) \pm S . \mathrm{E} .\end{array}$ & $\begin{array}{l}\text { Estimated } \\
\text { dry weight } \\
\quad(\mathrm{g} / \text { plant })\end{array}$ & $\begin{array}{l}\text { Number of } \\
\text { leaves } \\
\text { (No./plant) } \pm S . E \text {. }\end{array}$ & $\begin{array}{c}\text { Leaf area } \\
\left(\mathrm{cm}^{2} / \text { plant }\right) \pm S . E\end{array}$ \\
\hline High & $68.4 \pm 14.0$ & 5.33 & $3.3 \pm 0.7$ & $244.8 \pm 69.3$ \\
\hline Medium & $72.0 \pm 19.2$ & 5.62 & $3.4 \pm 0.9$ & $250.1 \pm 64.2$ \\
\hline Low & $76.6 \pm 20.2$ & 5.97 & $3.4 \pm 1.0$ & $239.2 \pm 70.1$ \\
\hline
\end{tabular}




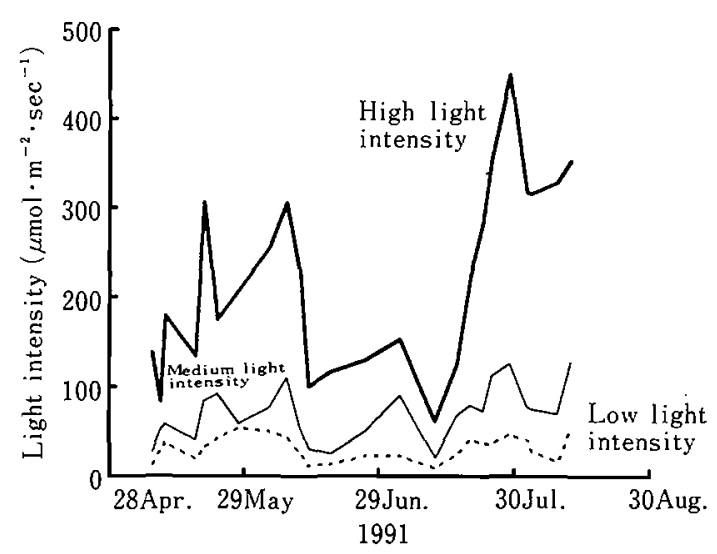

Fig. 1. Fluctuations in light intensities during the experimental growing period of Phalaenopsis.

きくなったが，曇天時には，遮光率とほぼ同比率の滅 光度となった。

光処理期間中の温室内の気温は最低 $20^{\circ} \sim 24^{\circ} \mathrm{C}$, 最高 $30^{\circ} \sim 38^{\circ} \mathrm{C}$ の範囲にあり（第 2 図），栄養生長の 促進のために十分（乼田・米田，1990）であった。一 方, 温度処理終了後の気温は, 最低 $20^{\circ} \sim 23^{\circ} \mathrm{C}$, 最 高 $26^{\circ} \sim 28^{\circ} \mathrm{C}$ の範囲にあり，この時期には花成誘導 可能温度域に達していたものと思われる。

\section{2. 栄養状態と生育}

葉の還元糖含有率は光処理間に差はなかったが，非 還元糖含有率は強光区で高かった（第 2 表），茎の還 元糖と非還元糖含有率は, 光処理間でほぼ一定であっ たが，還元糖含有率は他の部位と比較して著しく低い 特徵があった．根では光強度の增大に伴い高くなり， 特に還元糖含有率は著しく增加した。この結果, 全植 物体の還元糖, 非還元糖および全糖含有率は, 強光区 で最も高くなった。したがって，強光下では葉で多く の糖が合成され，それが根に多く流転し利用されるも のと考えられる.

葉と根の可溶性窒素含有率は強光区で明らかに低く なり，茎でも強光区で低くなる傾向にあった（第 2 表)，不溶性窒素含有率は，葉，菱，根ともに，光処 理間でほほ同じであったが，葉では荎と根よりも高か った，その結果，全植物体の不溶性窒素含有率は，光 処理間に差はなかったものの，可溶性窒素含有率が光 強度の増大に伴い著しく低下したため, 全窒素含有率 は低下した。

光処理期間中の乾物生産量は，光強度の低下により 著しく少なくなり，弱光区では実験開始時よりも軽く

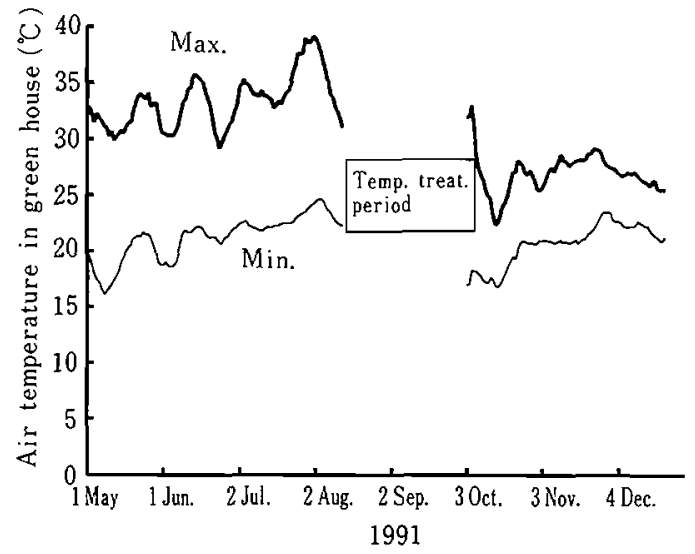

Fig. 2. Changes in ambient air temperature in the green. house prior to and after the three experimental day/night temperature treatments.

なった（第３表）．また, 窒素吸収量は強光区で最も 多くなり，さらに窒素 $1 \mathrm{mg}$ 当たりの乾物生産効率は 明らかに強光区で高まった。これは強光区では光合成 活性が高く，エネルギー源となる糖含有率が高いため， 窒素吸収量が多くなり，加えて吸収された窒素が可溶 性耊素から不溶性のタンパク態室素へ速やかに代謝さ れたためと考えられる，しかし，中光区と弱光区では 糖含有率が低いため，窒素吸収证が少なくなり，しか も吸収された等素は可溶性窒素として蓄積したため, 乾物生産量が少なくなったものと考えられる．

展開葉枚数および增加葉枚数は, 強光区と中光区で 多かったが, 展開葉面積と葉面積增加量は中光区で最 も多くなった（第 4 表）. 総根数は弱光区で少なく総 根長は強光区で長くなり, 光強度が強くなると根の生 育は促進された。したがって，葉枚数と葉面積增加量 で示される地上部の生育を促進させるためには，中光 区が好適であるものの，中光区と弱光区では比葉面積 が大きく，乾物率が低下していること（第 5 表）から 強光区に比べてやや軟弱な植物体となっていることが うかがえる。

葉面積の应大は，全植物体の全窒素含有率が約 1.5\%のときに促進されることが明かとなっている (篗田ら，1991). 強光区で葉面積が大きくならなかっ たのは，乾物生産星が多く相対的に植物体中の窒素濃 度が低下したためと考えられる．したがって，強光区 のように光強度が強い場合には，施肥量を増やし植物 体中の窒素濃度を高めることにより葉面積も大きくな るものと思われる。 
Table 2. Effects of light intensity on sugar and nitrogen contents in plant parts of Phalaenopsis.

\begin{tabular}{|c|c|c|c|c|c|c|c|}
\hline \multirow{2}{*}{$\begin{array}{l}\text { Plant } \\
\text { parts }\end{array}$} & \multirow{2}{*}{$\begin{array}{c}\text { Light } \\
\text { intensity }^{2}\end{array}$} & \multicolumn{3}{|c|}{ Sugar ( $\%$ dry weight) } & \multicolumn{3}{|c|}{ Nitrogen (\% dry weight) } \\
\hline & & Reducing & Non-reducing & Total & Soluble & Insoluble & Total \\
\hline \multirow{3}{*}{ Leaves } & High & 2.56 & 3.60 & 6.16 & 0.40 & 0.78 & 1.18 \\
\hline & Medium & 1.86 & 1.84 & 3.70 & 0.80 & 0.78 & 1.58 \\
\hline & Low & 1.23 & 1.67 & 2.90 & 0.83 & 0.83 & 1.66 \\
\hline \multicolumn{2}{|c|}{ Significance } & N.S. & ** & $*$ & $* *$ & N.S. & $*$ \\
\hline \multirow{3}{*}{ Stems } & High & 0.52 & 2.24 & 2.76 & 0.35 & 0.47 & 0.82 \\
\hline & Medium & 0.62 & 2.10 & 2.72 & 0.57 & 0.48 & 1.05 \\
\hline & Low & 0.49 & 2.34 & 2.83 & 0.59 & 0.50 & 1.09 \\
\hline \multicolumn{2}{|c|}{ Significance } & N.S. & N.S. & N.S. & N.S. & N.S. & N.S. \\
\hline \multirow{3}{*}{ Roots } & High & 5.13 & 4.71 & 9.84 & 0.66 & 0.60 & 1.26 \\
\hline & Medium & 2.19 & 2.53 & 4.72 & 0.79 & 0.48 & 1.27 \\
\hline & Low & 1.23 & 2.53 & 3.76 & 1.12 & 0.50 & 1.62 \\
\hline \multicolumn{2}{|c|}{ Significance } & $* *$ & $* *$ & $* *$ & $* *$ & N.S. & N.S. \\
\hline \multirow{3}{*}{$\begin{array}{l}\text { Whole } \\
\text { plant }\end{array}$} & High & 3.45 & 3.87 & 7.32 & 0.50 & 0.66 & 1.16 \\
\hline & Medium & 1.77 & 2.17 & 3.94 & 0.77 & 0.63 & 1.40 \\
\hline & Low & 1.11 & 2.03 & 3.14 & 0.87 & 0.69 & 1.56 \\
\hline \multicolumn{2}{|c|}{ Significance } & $* *$ & ** & $* *$ & $* *$ & N.S. & $*$ \\
\hline
\end{tabular}

2 Refer to Fig. 1.

y *: Significant at $5 \%$ level, **: Significant at $1 \%$ level. N. S.: No significant.

Table 3. Effects of light intensity on dry matter production, nitrogen absorbed and nitrogen efficiency in Phalaenopsis.

\begin{tabular}{lccc}
\hline $\begin{array}{l}\text { Light } \\
\text { intensity }\end{array}$ & $\begin{array}{c}\text { Amount of dry } \\
\text { matter products } \\
\text { (g/plant) }\end{array}$ & $\begin{array}{c}\text { Amount of nitrogen } \\
\text { absorbed } \\
(\mathrm{mg} / \mathrm{plant})\end{array}$ & $\begin{array}{c}\text { Nitrogen } \\
\text { efficiency } \\
\text { (mg dry matter/mg N) }\end{array}$ \\
\hline High & $1.72 \mathrm{a}^{y}$ & $36.0 \mathrm{a}$ & $47.7 \mathrm{a}$ \\
Medium & $0.15 \mathrm{~b}$ & $30.9 \mathrm{a}$ & $5.0 \mathrm{~b}$ \\
Low & $-1.50 \mathrm{c}$ & $11.0 \mathrm{~b}$ & - \\
\hline
\end{tabular}

Refer to Fig. 1.

y Different letters within columns represent significant difference $(\mathrm{P}<0.05)$.

Table 4. Effects of light intensity on growth of leaves and roots in Phalaenopsis.

\begin{tabular}{|c|c|c|c|c|c|c|c|c|}
\hline \multirow{2}{*}{$\begin{array}{l}\text { Light } \\
\text { intensity }\end{array}$} & \multicolumn{3}{|c|}{ Number of leaves } & \multicolumn{3}{|c|}{ Leaf area $\left(\mathrm{cm}^{2} /\right.$ plant $)$} & \multicolumn{2}{|c|}{ Total roots } \\
\hline & Expanded & Defoliated & Increased & Expanded & Defoliated & Increased & Number & Length $(\mathrm{cm} /$ plant $)$ \\
\hline High & $1.2 \mathrm{a}^{\mathrm{y}}$ & $0.5 \mathrm{a}$ & $0.7 \mathrm{a}$ & $87.5 \mathrm{~b}$ & $38.9 \mathrm{a}$ & $48.6 \mathrm{~b}$ & $14.0 \mathrm{a}$ & $196.6 \mathrm{a}$ \\
\hline Medium & $1.1 \mathrm{a}$ & $0.4 \mathrm{a}$ & $0.7 \mathrm{a}$ & $103.9 \mathrm{a}$ & $24.9 \mathrm{a}$ & $79.0 \mathrm{a}$ & $13.3 \mathrm{a}$ & $144.1 \mathrm{~b}$ \\
\hline Low & $0.8 \mathrm{~b}$ & $0.4 \mathrm{a}$ & $0.4 \mathrm{~b}$ & $69.7 \mathrm{c}$ & $23.7 \mathrm{a}$ & $46.0 \mathrm{~b}$ & $8.5 \mathrm{~b}$ & $123.1 \mathrm{~b}$ \\
\hline
\end{tabular}

$z$ Refer to Fig. 1.

y Different letters within columns represent significant difference $(P<0.05)$.

乾物生産量が最も多かった強光区の最大光強度は約 $400 \mu \mathrm{mol} \cdot \mathrm{m}^{-2} \cdot \mathrm{sec}^{-1}$ 以上であり, さらに実際栽培 では光強度を最大 $20 \sim 30 \mathrm{klux}$ (日中の全天放射とし
て換算した場合 336〜504 $\mu \mathrm{mol} \cdot \mathrm{m}^{-2} \cdot \mathrm{sec}^{-1}$ ) で管 理し, 高品質な収穫物を出荷している農家の実例もあ る (Vasquez, 1992). 一方, 本種の CAM 型光合成に 
最適な光強度は $12 \mathrm{klux}$ (須藤・筒井, 1989），光飽和 点は $130 \mu \mathrm{mol} \cdot \mathrm{m}^{-2} \cdot \mathrm{sec}^{-1}$ (約 $13 \mathrm{klux}$ ) であると の報告がある（太田ら，1991）。これらの実験は，一 定の光強度下で行われているが，実際栽培では太陽高 度や天候により，日中の光強度は大きく変動する。一 定の光強度下で導きだされた光合成に好適な光強度を， 実際栽培の最大光強度として管理した場合，光照射期 間中の総光エネルギー量は当然少なくなる。ちなみに, 強光区とほぼ同一条件下の 1992 年 7 月の 1 か月間の 光エネルギーを 10 分間ごとに自動的に測定し，この 数値を皘分して求めた 1 日当たりの平均総光エネルギ 一蛙は約 $3.86 \mathrm{~mol} \cdot \mathrm{m}^{-2} \cdot \mathrm{day}^{-1}$ であり,太田らが示 している光飽和点の条件 $\left(130 \mu \mathrm{mol} \cdot \mathrm{m}^{-2} \cdot \mathrm{sec}^{-1}\right.$, 12 時間日長) の総光エネルギー $\left(5.62 \mathrm{~mol} \cdot \mathrm{m}^{-2}\right.$. $\mathrm{day}^{-1}$ ) よりも少なかった。したがって，実際栽培条 件下で光合成量や生育量を最大にするための光強度は, 一定の光強度下の実験で得られた結果よりも強く管理

Table 5. Effects of light intensity on specific leaf area (SLA) and dry matter ratio in Phalaenopsis.

\begin{tabular}{|c|c|c|}
\hline $\begin{array}{l}\text { Light } \\
\text { intensity }\end{array}$ & $\begin{array}{l}\text { Specific leaf } \\
\text { area }^{y} \\
\qquad\left(\mathrm{~cm}^{2} / \mathrm{g}\right)\end{array}$ & $\begin{array}{c}\text { Dry matter } \\
\text { content } \\
(\%)\end{array}$ \\
\hline High & $99.4 \mathrm{~b}^{x}$ & $7.48 \mathrm{a}$ \\
\hline Medium & $119.3 \mathrm{a}$ & $6.97 \mathrm{a}$ \\
\hline Low & $129.3 \mathrm{a}$ & $5.93 \mathrm{~b}$ \\
\hline
\end{tabular}

2 Refer to Fig. 1.

Leaf area $\left(\mathrm{cm}^{2}\right) /$ dry weight $(\mathrm{g})$.

$x$ Different letters within columns represent significant difference $(P<0.05)$.
する必要があるものと考えられ，今後総光エネルギー 量の観点加光合成特性や生育特性を解析し，日長管 理や遮光方法を改善する（須藤ら，1991）必要性が認 められる。

\section{3. 花蒸発生}

各光処理区の $23 \% / 18^{\circ} \mathrm{C}$ 区の花茎発生は 9 月 23 日 に始まり，花荎発生率は弱光区と中光区では約 $60 \%$ ， 強光区では約 $80 \%$ となった (第 3 図). 弱光抢よび中 光区の $28 \% / 23^{\circ} \mathrm{C}$ 抢よび $33 \% / 28^{\circ} \mathrm{C}$ 区と, 強光区の $33^{\circ}$ $128^{\circ} \mathrm{C}$ の花荎発生は 11 月 10 日前後であり，この花荎 発生は温度処理の影榔ではなく温度処理後に移入した 温室の気温が花茎誘導可能温度域に達していたためと 考えられる．強光区の $28 \% / 23^{\circ} \mathrm{C}$ 区の花荎発生は 10 月 8 日に始まり，弱光区と中光区よりも明らかに発生 時期が早まった。

アザレアや低温要求性のペラルゴニウムでは，光強 度の増大は，花芽分化の促進または低温などの開花誘 導要因を補完する作用を持つことが明らかになってい る (Bodson, 1983; Hackett・Kister, 1974)。本実験で も温度処理前の光強度が強い場合，処理温度が花成誘 導に対して十分であれば花茎発生率を高め，処理温度 が花成誘導の限界温度域（米田，1985）であれば，花 荎の発生時期を早める結果となり，栄養生長期間中の 光強度を強くすることにより，花成誘導の温度感応性 を高めることができると考えられる。

花熟を検討した実験のうち，低温に感応して花荎が 伸長を開始するためには，株が前の開花後ある程度生 長をつづけた後であること（石田・坂西，1974），若 齢株では花成誘導が不完全になりやすいことが明らか

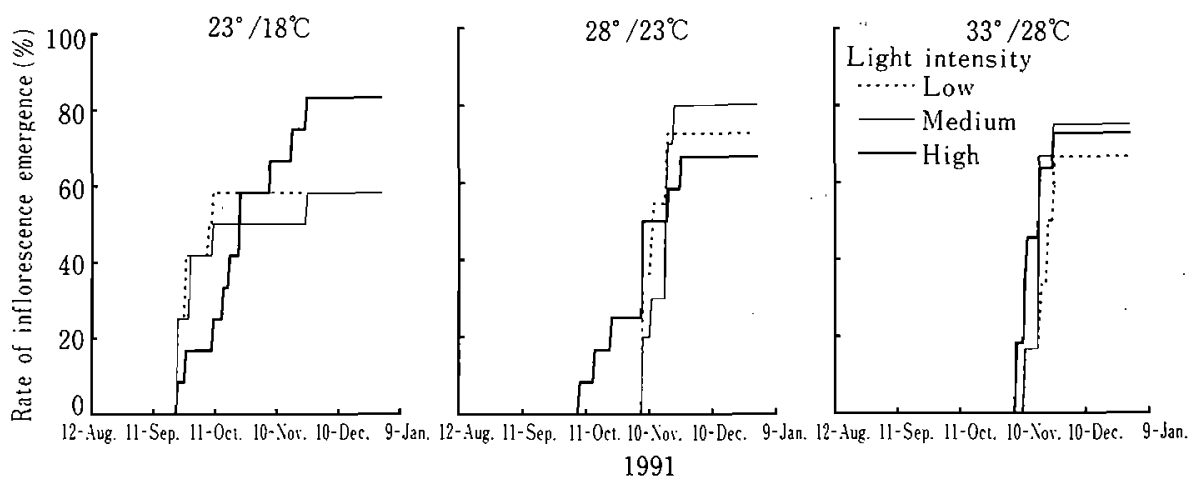

Fig. 3. Effects of three day/night temperatures on the time of flower emergence of Phalaenopsis plants exposed to high, moderate and low light intensities. The number of inflorescences of the plants under high light intensity increased at $23 \% 18{ }^{\circ} \mathrm{C}$. but their emergence was accelerated at $28 \% / 23^{\circ} \mathrm{C}$. 
にされている（米田ら，1992）。本種は葉を展開する ことにより将来花茥となる腋芽を形成することから， 葉の展開は花荎発生に対して必要条件である. しかし, 本実験結果から花成を促進させるためには，葉の展開 量の増大のほかに，糖などの炭水化物含量を高め相対 的に C/N率を高くするなどの植物の栄着状態も大き くかかわっていることが指摘できる。

\section{摘 要}

本実験はファレノプシスの花成誘導前の生育期間中 の光強度が，温度処理による花成誘導に及ぼす影響に ついて，植物栄荃生理学的な側面から明らかにしよう としたものである。

糖含有率と法素吸収量は強光区で増大したが，逆に 全窒素含有率は最も低くなった，展開葉数，根の生育 および乾物生産量は強光下で最も旺盛となった。

花萃誘導のための温度処理前に, 強光条件下で生育 した植物は， $23 \% 18{ }^{\circ} \mathrm{C}$ では花菱発生割合が增加し， $28 \% 23{ }^{\circ} \mathrm{C}$ では花茎発生時期が早まった。したがって, 花成誘導に対する温度感応性は， $C / N$ 率が高く乾物 生産量が多い株で高くなる傾向か認められた。

したがって，ファレノプシスの花成誘導の温度感応 性を高めるためには，植物体内の糖含有率を高くし， 円滑な窒素代謝を促進するように，比較的強光下で栽 培する必要があるものと考えられた。

\section{引用文献}

Bodson, M. 1983. Effects of photoperiod and irradiance on floral development of young plants of a semiearly and a late cultivar of Azalea. J. Amer. Soc. Hort. Sci. $108:$ :382-386.

福井作蔵. 1990. 生物化学実験法 1. 還元糖の定量法. p. 9-11. 学会出版センター. 東京.

Hackett, P. W. and J. Kister. 1974. Environmental factors affecting flowering in Pelargonium domesticum cultivars. J. Amer. Soc. Hort. Sci. 99 : 15-17.

樋口春三・酒井広蔵. 1978. 山上げ栽培によるファレ ノプシスの開花促進について．爱知農総試研報。 B $10: 42-45$.

井上喜雄・桶口春三. 1988. 人工光（人工太陽照明 灯）照射によるファレノプシスの開花誘導．園学
要旨. 昭 63 春 : $370-371$.

稲田勝美. 1984. 光と植物生育. p. 389. 養賢堂。東 京.

石田源次郎・坂西義洋. 1974.ファレノプシスの生育 開花習性と温度の影響について，園学要旨。昭 49 秋 : 298-299.

窐田 聡・米田和夫. 1990.ファレノプシスの生育並 びに養分吸收に及ぼす温度と施肥の影響. 園学雑. 59 (別 1) : 554-555.

寉田 聡・浅井重雄・米田和夫. 1991. ファレノプシ スの生充・開花に及ぼす望素施与時期の影脢。園 学雑. 60 (別 2) : 472-473.

松永俊朗・塩崎尚郎. 1989. 硝酸態窒素を含む作物中 の全空素定量のための硫酸一過酸化水素分解法. 土肥誌. $60: 458-460$.

太田弘一・森岡公一・山本幸男. 1991. ファレノプシ スにおける CAM 型光合成への菜龄・花序・水分 - 温度・光条件の影帮. 園学雑. $60: 125-132$.

大山卓爾. 1990. 空素化合物分析法. インドフェノー ル法による $\mathrm{NH}_{4}{ }^{+}$の比色定量. p. 175-177. 植物 栄養実験法編集委員会編. 植物栄養実験法. 博友 社. 東京.

Sakanishi, Y., H. Imanishi and G. Ishida. 1980. Effect of temperature on growth and flowering of Phalaenopsis amabilis. Bull. Univ. Osaka Pref. Ser. B $32: 1-9$.

須藤憲一 - 中村浩美 - 篠田浩一. 1991. 鉢花の遮光方 法の改善. 野菜茶試花き部年報。 $5: 72-76$.

須藤憲—・筒井 澄, 1989. CAM 植物 (ファレ)プ シス・ホシクジャクサボテン) の炭酸ガス収支に 及ぼす光量の影響. 園学要旨. 昭 55秋: 318-319.

Vansquez, G. 1992. Commercial growing of Phalaenopsis. p. 80-86. 名古屋国際䍘展 '92 組織 委員会. 名古屋国際荋展'92 記録. 名古屋国際䕥 展'92 組織委員会事務局. 名古屋.

山崎肯哉. 1982 . 養液栽培全編. p. 107. 博友社. 東 京.

米田和夫. 1985. 株齢と山上げ姏理時期の違いがブァ レノプシスの開花に及ぼす影愔. 園学雑. 54 ： 101-108.

米田和夫・百瀬博文・熦田 聡. 1992.ファレノプシ スの株龄の違いが開花に及ぼす温度の影䍌. 熱帯 㟽業. $36: 207-210$.

吉野 実. 1975. 炭水化物の分別定王法. 還元糖, 全 糖の定量. p. 332. 作物分析法委員会編. 栄養診 断のための栽培植物分析測定法. 養賢堂. 東京. 